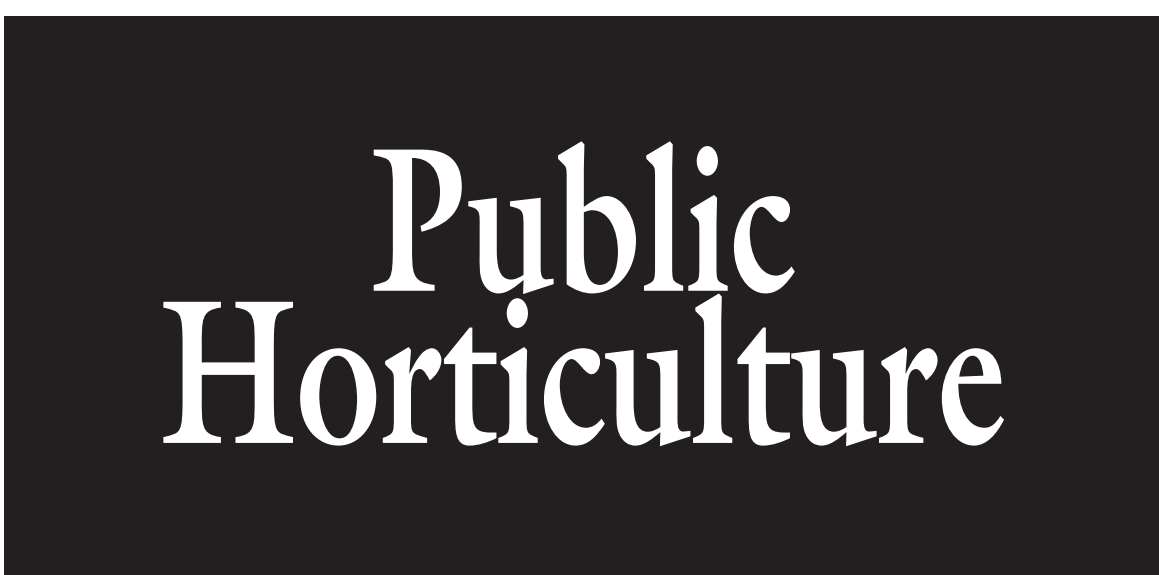

\title{
Survey Responses Identify Community Member Interest in Visiting Public Gardens and Arboreta
}

\author{
Kathleen M. Kelley ${ }^{1,3}$, James C. Sellmer ${ }^{1}$, and Rebecca H. Robert ${ }^{2}$
}

ADDITIONAL INDEX WORDS. consumer attitudes, behaviors, Internet, membership, programs

Summary. An Internet survey was conducted from 28 May to 8 June 2008 to investigate consumer awareness and interest in attending programming offered at The Scott Arboretum of Swarthmore College (Swarthmore, PA). The study was designed to investigate what traditional and non-traditional programs might attract community members to the arboretum and to identify potential barriers, perceived or real, that might discourage community members from visiting the arboretum. Among demographic groups, more females were interested in "hands-on workshops" (42.5\%) and "fact sheets, instructional bulletins, and how-to guides" (37.4\%) than males $(26.8 \%$ and $26.3 \%$, respectively). In examining events and activities, significant differences were found for "wine tasting and tours" and "outdoor concerts and live performances" based on household income; however, no significant differences were found among age groups and other demographics tested. Differences in interest in other activities were apparent based on number of adults and number of children in the household. Public gardens and arboreta can use this information as the foundation for modifying programs and services offered, though input from the community and trialing of alternative programs should be considered before completely changing programs and services offered.

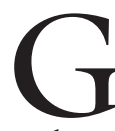
ardens, landscapes, and interiorscapes have been recognized by several researchers and organizations to have a positive impact on human beings and their

\footnotetext{
Department of Horticulture, The Pennsylvania State University, University Park, PA 16802 and The Scott Arboretum of Swarthmore College, Swarthmore, PA 19081

This study was funded by The Scott Arboretum of Swarthmore College.

The mention of trade names does not imply endorsement of the products named or criticism of similar ones not named.

${ }^{1}$ Associate Professor.

${ }^{2}$ Member and Visitor Programs Coordinator.

${ }^{3}$ Corresponding author. E-mail: kmk17@psu.edu.
}

and arboreta as a resource and destination and how these spaces should structure events, activities, education, and entertainment to best coincide with consumer interests. Thus, public gardens and arboreta can provide visitors with benefits beyond pleasing views and decor. With so many benefits to offer, it would be expected that these natural spaces would draw a variety of audiences on a regular basis. However, it may be that either consumers are unaware of these benefits, or else they consider public gardens and arboreta as locations that would offer activities only for gardeners interested in landscapes and ornamentals. It may also be that pubic gardens and arboreta personnel self-limit their perspective of what they have to offer, or should offer, the public.

Conventional wisdom might suggest that recent gardening trends, based on a $19 \%$ increase in households participating in food gardening, of which $21 \%$ were new gardeners (Butterfield, 2009), could provide a new focus for public gardens and arboreta programming efforts. It is possible that public gardens and arboreta would alter current marketing and educational programs to capitalize on such a trend; however, the question remains as to whether incorporating relevant food gardening topics into current curriculum will increase foot traffic and gate receipts. Gardening is often influenced by culture, the environment, the economy, and present personal interest (Price, 2000), which may change over time. Public gardens compete with entertainment and retail industries for visibility and consumer discretionary income (Tamulevich, 2006). Thus, market research and analysis should follow a strategy in defining the interest of the developing target market and develop programming to appeal to this audience.

Some facilities are proactive in providing these services, such as the following: Holden Arboretum, Kirkland, OH; The Scott Arboretum of Swarthmore College, Swarthmore, PA; Morris Arboretum at the University of Pennsylvania, Philadelphia, PA; and Klehm Arboretum and Botanic Garden, Rockford, IL. These public gardens have offered the venue or space for non-gardening (wine tastings or outdoor concerts) or peripheral horticultural events (farmers' market, treeclimbing schools), which may attract a more robust non-traditional audience, 
resulting in increased attendance, membership, and revenue, and encourage repeat visits.

The goal of this study was to investigate how to attract community members to arboreta and public gardens, specifically, by asking what traditional and non-traditional programs might appeal. In addition, this study was designed to identify potential barriers, perceived or real, that might dissuade community members from visiting arboreta and public gardens. It is expected that results will encourage program coordinators and program directors to further define needs, wants, and interests of those living in their community to increase visitation, repeat visits, membership, and revenue.

\section{Materials and methods}

An Internet survey of consumers residing within a 30 -mile $(48.3-\mathrm{km})$ radius of Swarthmore, PA, was conducted from 28 May to 8 June 2008 to investigate consumer awareness and interest in attending the programming offered at The Scott Arboretum of Swarthmore College (Scott Arboretum) situated on the Swarthmore College campus. The survey was designed to define factors that influence respondent decision to participate in leisure activities and events offered at the arboretum and to identify interest in existing and future programs and services offered by the arboretum staff. The survey was a component of an assessment conducted by the American Association of Museums (2010).

The survey instrument was developed using SurveyMonkey (Palo Alto, CA), an online survey tool. The survey was pre-tested on a subset of the target consumer population to refine and clarify misleading or misunderstood questions before full deployment. Survey participants were recruited within the target region as identified by arboretum staff based on past traffic data as a reasonable distance to travel for leisure activities at the arboretum. Participants who resided in metropolitan Philadelphia were selected at random from a recognized consumer panel managed by Survey Sampling International (Shelton, CT), a provider of sampling solutions for survey research. Panelists received an email consent statement along with a link to the survey developed by researchers and approved by the Office of Research Protections at The Pennsylvania State
University (University Park, PA). All potential participants were screened and asked to participate if they were age 21 years and older to ensure that independent adults participated and because questions concerning alcoholrelated events were asked. Panelists were informed of this criterion and their compensation, an entry into Survey Sampling International's quarterly $\$ 25,000$ sweepstakes and an instantwin game play, which is a standard compensation for these panelists, in the consent statement. To begin the survey, panelists clicked on a hyperlink at the bottom of the consent statement, which then directed them to the survey welcome screen.

Of the 547 members registered with this panel and who met the screener criteria and began the questionnaire, 502 members completed the survey, which took an average of $10 \mathrm{~min}$ to finish. Panelists responded as to whether they were familiar with the arboretum, whether they had visited Scott Arboretum and/or the Swarthmore College campus in the past, whether they had barriers to attending leisure activities (e.g., time of day and day of week these activities were held, associated costs, distance needed to travel, available childcare at the event), whether they were ever arboretum members, whether they had interest in leisure activities and events (e.g., gardening, landscaping, and lawn care; wine tasting; nature hikes; gardening topics for children), and whether they had perceived proficiency and interest in gardening, and about their demographics (e.g., age, gender, 2007 annual gross household income, household size). Questions were adapted from the National Gardening Association's "What Gardener's Think Survey" (Butterfield, 2006) to better understand what "type" of gardener or "gardening experience" the community members possessed. After participants submitted their completed survey, they were directed to a "thank you" page.

\section{Statistical analysis}

Data pertaining to consumer behavior and preference questions were analyzed with SPSS (version 17; SPSS, Chicago, IL) using Pearson chi-square statistic, Kruskal-Wallis one-way analysis of variance (ANOVA), and MannWhitney $U$ test $(P \leq 0.05)$. Pearson chi-square tests were used to assess differences in the proportion of participants' responses to question such as past visits to the facility. Kruskal-Wallis one-way ANOVA was used to test mean differences among groups for questions such as interest in programs and activities, followed by Mann-Whitney $U$ test, which was used to test difference for means between two groups.

\section{Results and discussion}

Demographic profile. Of the 502 participants, the most common responses to demographic questions were from female $(59.8 \%)$, members of a two-adult household (49.7\%), those with no children $(70.1 \%)$, those between ages 49 and 64 years $(44.5 \%)$, those with a college education $(46.0 \%)$, and those with a household income of $\$ 75,999$ or lower (59.4\%).

AWARENESS AND IMPRESSION OF THE ARBORETUM. Only $10.4 \%$ of survey participants reported visiting Scott Arboretum; hence, one possible reason for the low rate of visitation may be lack of familiarity with the arboretum. A majority $(74.9 \%)$ was not familiar with the arboretum, with more females $(78.2 \%)$ indicating that they were less familiar with the arboretum than males (69.2\%) (Table 1). A solution for this lack of awareness would be a more active and targeted marketing effort within the community surrounding the arboretum. No significant differences were found, with average responses, for "location is not convenient for me to visit" $(21.7 \%)$, "has not had an interest in programs offered" (11.4\%), "program costs prevent attendance" (3.8\%), "days and/ or times of programs are not convenient" $(4.0 \%)$, and "other membership prevents me from attending programs" $(2.8 \%)$ based on demographic status or membership in other associations.

FACTORS THAT INFLUENCE PARTICIPATION IN LEISURE ACTIVITIES AND EVENTS. Community members were asked to respond to statements as to whether it would restrict their willingness to visit the arboretum (e.g., "personal interest," "accessible parking," "child care during the activity or event"). When responses to these statements were analyzed based on demographic characteristics, some significant differences were detected. Female community members were more likely to consider "costs associated with participating in or attending" compared with males $(75.9 \%$ and $59.1 \%$, 


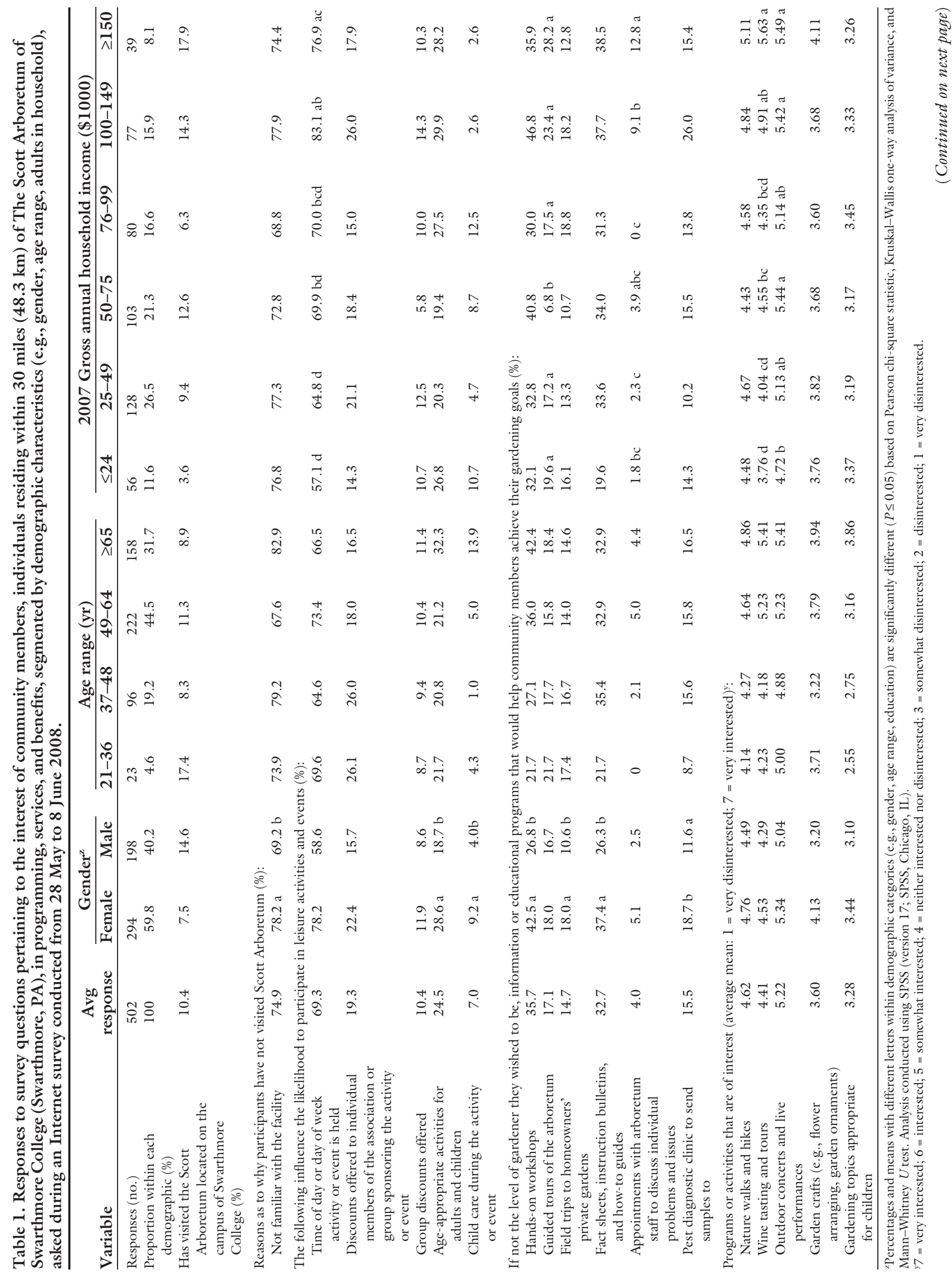




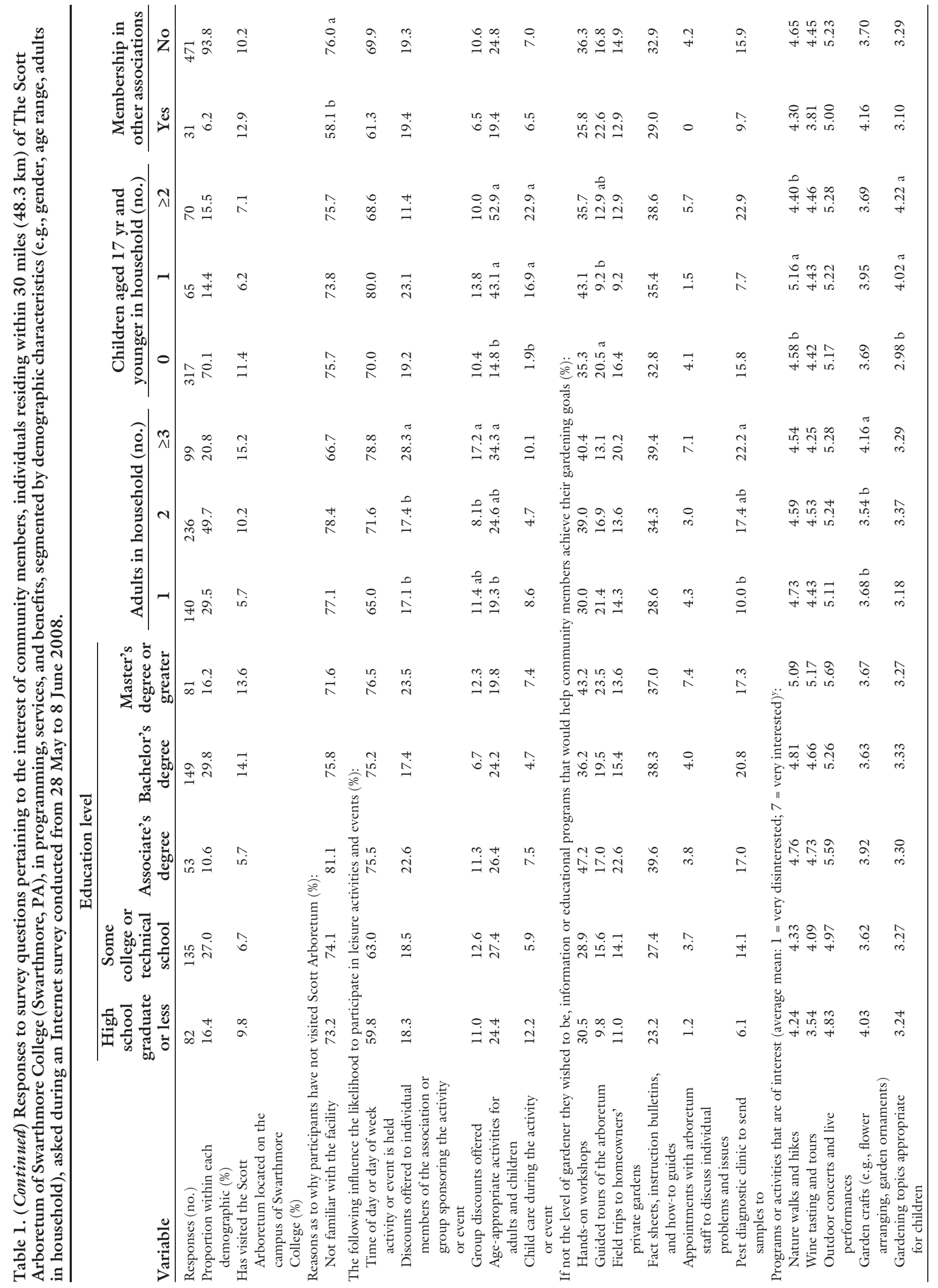


respectively) (Table 1). Similarly, "personal interest" was more important to females $(75.5 \%)$ than to males $(62.6 \%)$. In discussing discounts, households with three or more adults reported being influenced by member discounts (28.3\%) and group discounts (17.2\%) closely followed by single participants (17.1\% and $11.4 \%$, respectively, based on discount type) or two-adult households $(17.4 \%$ and $8.1 \%$, respectively, based on discount type). "Time of day or day of week activity or event is held" yielded significant differences based on income level, with consumers who reported 2007 household incomes of $\$ 150,000$ or greater $(76.9 \%)$ citing this as more of an influence on participating in leisure activities and events than those who reported earning $\$ 75,999$ and less (range of $57.1 \%$ to $69.9 \%)$.

Households with children were influenced by the availability of "age appropriate activities," with two or more children $(52.9 \%)$ and single-child households (43.1\%) being most motivated than households without children (14.8\%). "Child care during the activity or event" also yielded differences based on number of children per household, with households having two or more children $(22.9 \%)$ and one child $(16.9 \%)$ responding that these activities influenced attendance. No differences were detected for "distance needed to travel to the activity or event" $(69.7 \%)$ and "accessible parking" $(36.3 \%)$.

INTEREST IN GARDENING. Questions were designed to better understand participants' self-described level of knowledge and interest in gardening. In general, greatest percentage (32.1\%) of community members responded that they equally "enjoy gardening and other activities and hobbies." In other words, gardening competes equally with other activities for the survey respondents' interest (Table 2). In contrast, $22.3 \%$ of respondents stated that they "did not consider themselves gardeners" and that they devoted more time to other activities and hobbies. Among respondents, only $17.7 \%$ considered themselves "passionate about gardening" and interested in learning more about gardening topics. On the basis of these responses, arboreta and public gardens should consider broadening their offerings beyond gardening and landscaperelated topics to appeal to consumers with multiple interests and/or minimal interest in gardening.

Of the respondents, $15.7 \%$ considered themselves "skilled and knowledgeable gardeners." This group may be the target market for membership, volunteer, and docent programs. Among this group, differences were based on demographic characteristics. A trend was apparent based on gross annual household income. As income level increased, the percentage of "skilled and knowledgeable gardeners" decreased. Members with a 2007 gross annual household income of $\$ 24,999$ or less $(28.6 \%)$ were more likely to select "skilled and knowledgeable gardeners" than those in the income categories of $\$ 76,000$ and above (range of $5.1 \%$ to $11.3 \%$ ) (Table 2 ). Community members with a household income of $\$ 25,000$ to $\$ 49,999(19.5 \%)$ and $\$ 50,000$ to $\$ 75,999(18.4 \%)$ were also more likely to select the "skilled and knowledgeable gardeners" category than those with an income of $\$ 100,000$ and above. Skill and knowledge differences were also apparently based on number of adults in the household. A greater percentage of single-adult households (22.9\%) selected "skilled and knowledgeable gardeners" compared with households with two adults (11.0\%).

Programming and Services to INCREASE GARDENING EXPERTISE. To identify additional programming and services that arboretum staff could offer, participants were asked to indicate that if they were not at the level of gardener they wished to be, what information or educational programs they believe would help them achieve their gardening goal. Significantly, more females were interested in "hands-on workshops" $(42.5 \%)$ and "fact sheets, instructional bulletins, and how-to guides" $(37.4 \%)$ than males $(26.8 \%$ and $26.3 \%$, respectively).

"Guided tours of the arboretum" was significantly less popular among consumers with an income range of $\$ 50,000$ to $\$ 75,999$ (6.8\%) than all other income groups (range of $17.2 \%$ to $28.2 \%$ ) (Table 1 ). "Guided tours of the arboretum" was less popular with single-child households (9.2\%) than childless households. This limited interest by single-child households may be due to more interest in child-focused activities, where children would have the opportunity to interact with their peers, rather than large-group tours or tours in general.

More female participants were interested in "pest diagnostic clinic" (18.7\%) compared with males (11.6\%), and a greater percentage of respondents who live in households with three or more adults (22.2\%) were interested in this service compared with single-adult households (10.0\%), but neither of these segments were different from two-adult households (17.4\%) (Table 1).

Gender was the only demographic group that exhibited significant differences to "field trips to homeowners' private gardens." Within this demographic, more females (18.0\%) were interested in this activity than males (10.6\%).

No significant differences, based on demographic status or membership in another association, were detected for "electronic resources (e-newsletters, blogs, online how-to videos)" (37.4\% based on responses from all participants), "field trips to other public gardens and arboreta" (16.5\%), and "lectures" (9.6\%).

COMPLEMENTARY PROGRAMS AND SERVICES OF INTEREST. Over one-third of the participants selected categories with less emphasis on gardening. On the basis of this response, it would be prudent for arboreta and botanic gardens to consider and identify other activities. To this end, participants were asked to respond to series of activities and events on a seven-point Likert-type scale ( $7=$ "very interested" and 1 = "very disinterested").

In examining events and activities, significant differences were found for "wine tasting and tours" and "outdoor concerts and live performances" based on household income; however, no significant differences were found among age groups and other demographics tested. Community members who reported that their 2007 gross annual household income was $\$ 150,000$ or greater had a mean rating of 5.63 for "wine tasting and tours," which was between "interested" and "slightly interested" and was greater than those who responded that they had an income of $\$ 99,999$ or less (Table 1). Respondents with an income level ranging from $\$ 100,000$ to $\$ 149,999$ were lukewarm to wine tasting with a mean rating of 4.91 , which was between "slightly interested" and "neither interested nor 


\section{Public Horticulture}

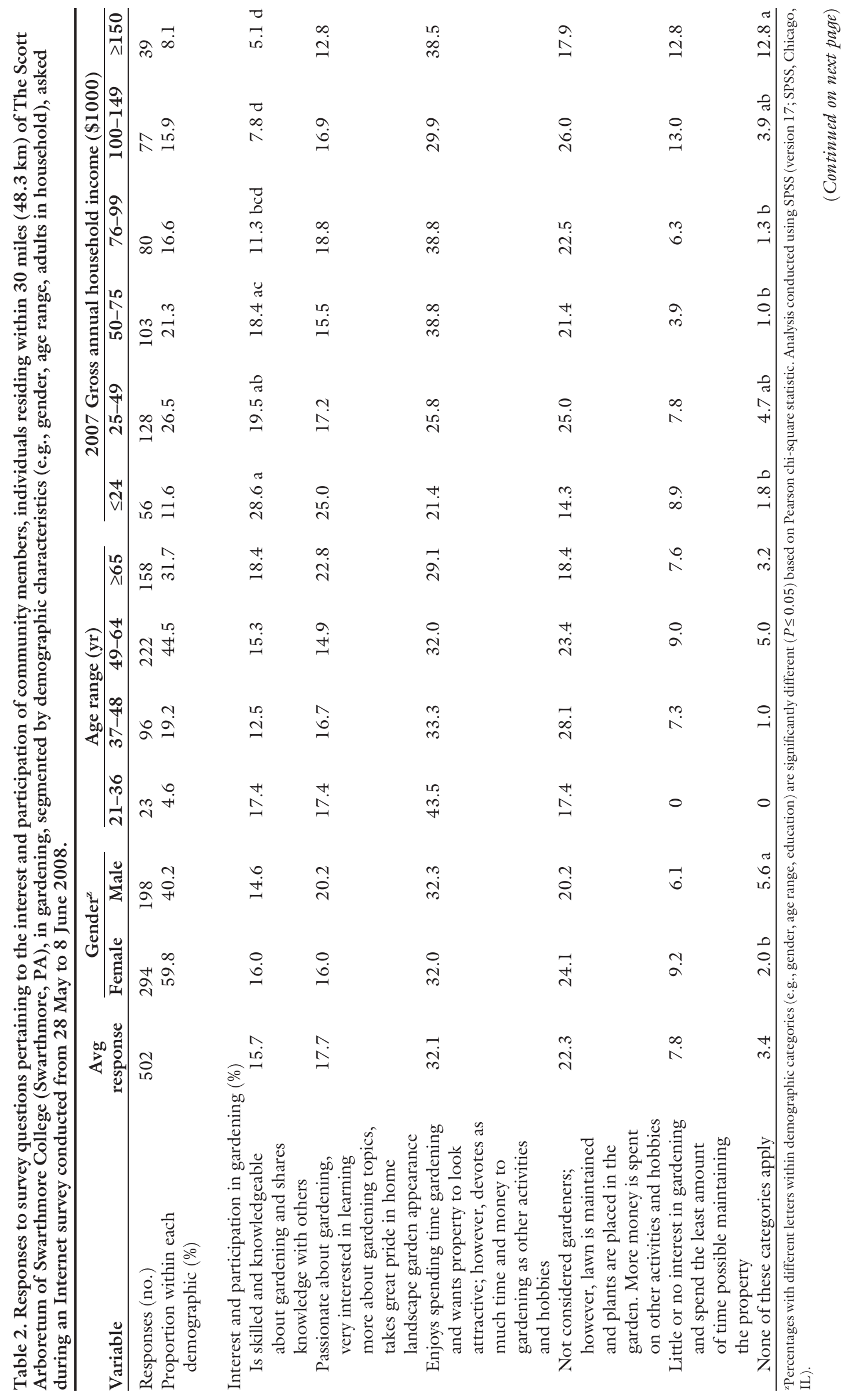




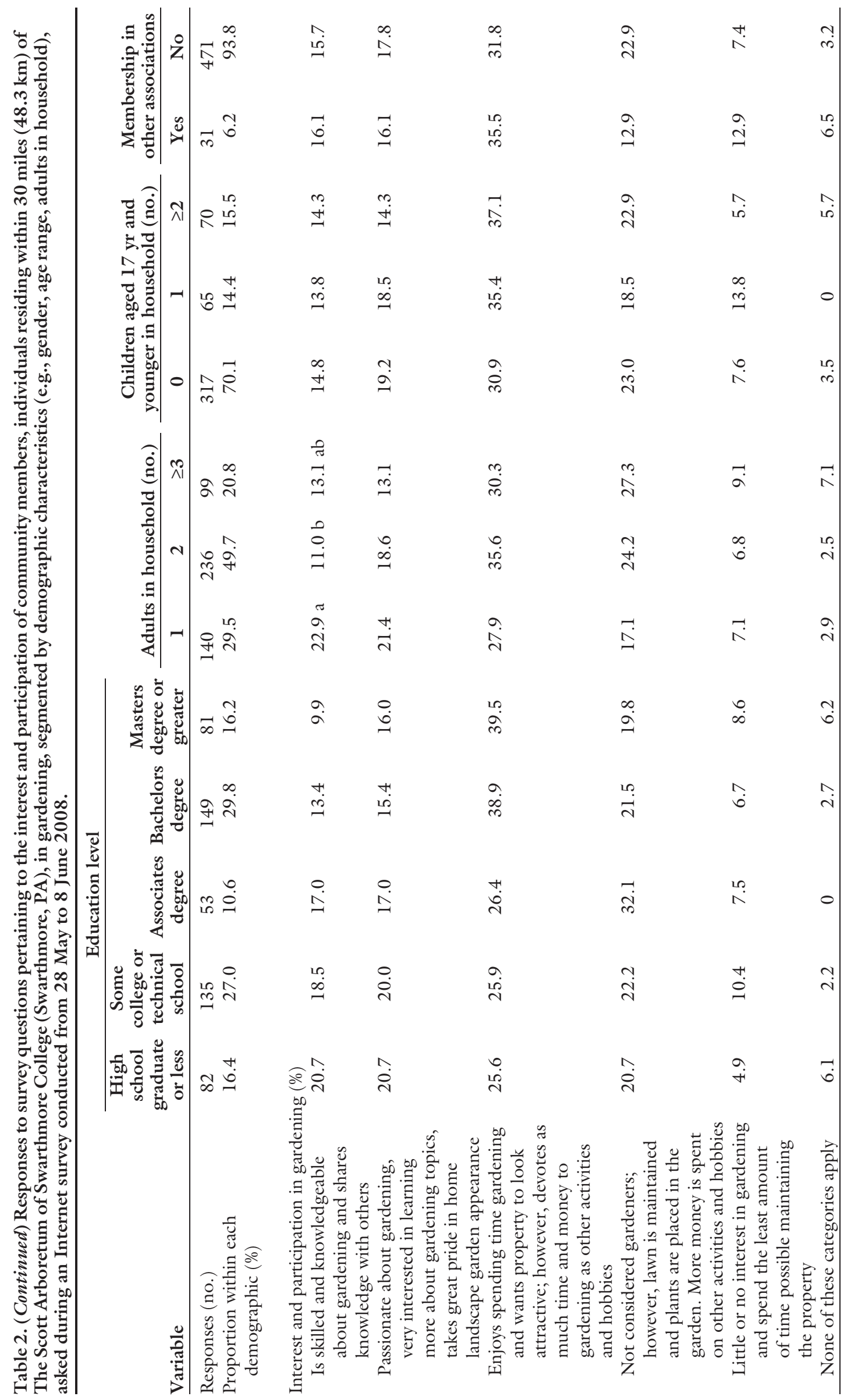


disinterested" and was greater than those with an income of $\$ 75,999$ or less. Community members with an income level between $\$ 50,000$ and $\$ 75,999$ had a mean rating of 4.55 and were generally lukewarm, and those with income levels of $\$ 24,000$ and less were less interested (3.76 mean rating) in wine-tasting events. "Outdoor concerts and live performances" was less preferred by participants with an income level of $\$ 24,999$ or less with a mean rating of 4.72 , which was between "somewhat interested" and "neither interested nor disinterested" and was significantly different from those with an income of $\$ 50,000$ to $\$ 75,999$ (mean rating of 5.44 ) and $\$ 100,000$ or greater (range of 5.42 to 5.49 ).

Interest in "garden crafts" differed based on number of adults in the household, with households containing three or more adults responding more positively (mean of 4.16 ) than single-adult households (mean of 3.68) and two-adult households (mean of 3.54) (Table 1). Similarly, households with children were more interested in "gardening topics appropriate for children" (mean of 4.22 for households with two or more children and mean of 4.02 for households with one child) compared with households without children (mean of 2.98). Two-adult households were more likely to respond positively to "nature walks and hikes" (mean of 5.16) compared with single-adult households and households with three or more adults (means of 4.58 and 4.40, respectively).

In response to "cooking and entertaining" (average mean based on all responses, 4.77), "gardening, landscaping, and lawn care" (4.30), "vegetable gardening" (4.21), "indoor gardening" (4.09), "garden books and book clubs" (3.60), "painting and drawing" (3.51), and "birding" (3.36), no significant differences were found based on demographic status or membership in another association.

\section{Conclusion}

In this survey, participant demographics exhibited similarities to a study conducted by the Travel Industry Association, as reported in Benfield (2006), where public garden visitors in 2003 "were generally college educated, had a higher income, were older and more likely to be married." This being the case, promotional materials for events and programs directed toward garden members may be equally applicable to a greater community. A targeted promotional campaign directed toward neighborhoods and communities with a large identifiable member or visitor population may entice large community members to visit the local public garden or arboretum.

With survey participants residing within a 30-mile radius of Scott $\mathrm{Ar}$ boretum, it became obvious that a minority of the respondents had visited or were aware of the arboretum within their community. As a first effort to define the market and quantify consumer awareness and interest, this study has identified important information that can serve 1) as the foundation for selecting traditional and non-traditional programs, events, and activities; 2) to target audience likely to have an interest in attending; and 3 ) to understand how best to promote these offerings to the target audience.

In a broader perspective, the following question must be asked of all arboreta and botanic gardens: How do you market and are your marketing methods reaching your potential audience and their interests? According to a 2005 study conducted by the American Public Garden Association and member gardens (Benfield, 2006), of the 3000 visitors surveyed, $24 \%$ of consumers stated that they learned about the garden they visited through "word of mouth," followed by periodicals $(25 \%)$, web sites developed by public gardens and related industries (10\%), brochure $(9 \%)$, and direct mailings $(7 \%)$. Though it can be argued that consumers are still strongly influenced by word of mouth (Sernovitz, 2009), it is possible that a greater number of consumers are learning about public gardens and arboreta through this source as the availability and use of the Internet has increased in recent years (Edwards, 2009). Hence, public gardens and arboreta should frequently survey their visitors and members about preferred methods of communication.

In this case, it appears that a stronger marketing effort should be developed and deployed with further surveying and evaluation of impact. A majority of community members responded that "personal interest" is the primary influence on their participation in activity and events. Thus, it is important that arboreta and botanical garden program coordinators/directors should truly strive to understand current and potential visitors' interest in programs, trial selected programs, and base future offerings on response and reaction. From this survey, it appears that the stereotypical offerings from arboreta and botanic gardens relative to gardening lectures, tours, and outreach landscape management and maintenance may not be the most attractive activities and entertainment to offer in seeking to attract new and repeat visitors with a more diverse outlook on life.

Other barriers to visiting the garden or arboretum, such as price and the distance consumers need to travel to attend, should be taken into consideration to develop a package that will be appealing. Pricing strategies such as offering hour-long programs delivered by staff or volunteers could be offered for free to introduce community members to topics, with more extensive programming offered for a fee. Alternatively, related programs could be offered on the same day, either in sequence or concurrently, to allow attendees to attend multiple programs during a single visit to the garden (Klemmer and Skelly, 2006). True demand, on the basis of attendance, should be assessed, with adjustments made if necessary.

It is apparent from the participants' selection of gardening category that best fits their interest and skill level that more than half of the community members had at least some interest in gardening. This being the case, a tiered level of programming (e.g., basic and advanced education) may be necessary to appeal to the difference in knowledge level among the target audience. How consumers wish to learn about gardening and other subjects taught by staff does vary. With responses and interest split between tours, trips, and pest diagnostic clinics, all of which received less than $20 \%$ responses, program coordinators and management will need to assess the costs and benefits of offering each service. Questions to consider are as follows: Is current staff prepared to offer these services with expertise and time available? What are the transportation costs associated with transporting attendees off property? How 
might staffing be handled if employees are required for both daily operations and to lead these activities? Also, will the costs of the service meet, exceed, or be less than the expected? Since one service did not receive an overwhelming percentage of responses, it may be necessary to investigate other services or to develop a tentative tour/ trip and ask community members to respond to the offering.

Benfield (2006) stated that the "garden audience" is probably not best described based on demographics, rather psychographics (interests) and behaviors warrant further investigation in "defining the garden visitor." As noted earlier, almost a third of the community members selected response categories that indicated low or no interest in gardening, which is supported by statements written by Klemmer and Skelly (2006) in their assessment of today's gardening audience. The authors indicated that "large scale events and phenomenal exhibits" can entice consumers to visit a garden and that while exploring the grounds they may develop an appreciation for plants and the landscapes. Thus, exploring activities, events, educational programming, and additional uses for the space is a reasonable action. With $75 \%$ of community members stating some level of interest in outdoor concerts and live performances, it is not just the non-gardeners who should be targeted with invitations to and advertisements about these events. Taking into consideration other topics that a majority of participants indicated some level of interest in, cooking and entertaining, nature walks and hikes, and wine tasting could also be explored as an offering. Staff may decide to strengthen the relationship between the gardens and these classes/activities by using food grown on the property in cooking and entertaining demonstrations, as well as suggest how these foods might be paired with wines served. As consumers with higher levels of income were more likely to show interest in wine tasting and tours, some investigation should be done to identify wineries and wines that may be more appealing to consumers with a higher income. A key component may be to develop a rotating schedule that is used as the basis for changing displays, exhibits, and offerings to encourage repeat visits (Tamulevich, 2006).

These strategies should be used as guidelines for arboreta and public gardens. As our sample was drawn from a community in an urban setting, gardens and arboreta in more suburban and rural areas may find that community members have different interests and desire other services. Before completely implementing an idea and investing great amounts of time and money, it is best to trial an idea and base the programming decision on direct community response. Changing programming takes time, and as with all entertainment and retail operations, it takes planning and continual evaluation over several years to provide reliable feedback and to understand the interests and characteristics of the audience.

\section{Literature cited}

American Association of Museums. 2010. Museum Assessment Program. 14 May 2010. <http://www.aam-us.org/ museumresources/map/index.cfm $>$.

Benfield, R. 2006. Who are our visitors... and what do they like? Public Garden $2 \mathrm{l}(2): 7$.

Bennett, E.S. and J.E. Swasey. 1996. Perceived stress reduction in urban public gardens. HortTechnology 6:125-128.

Butterfield, B. 2006. What gardeners think. National Gardening Assn., South Burlington, VT.

Butterfield, B. 2009. The impact of home and community gardening in America. National Gardening Assn. 12 Aug. 2009. <http://gardenresearch.com/files/2009Impact-of-Gardening-in-America-WhitePaper.pdf $>$.

Edwards, T. 2009. Internet use triples in decade, Census Bureau Reports. 10 Nov. 2009. <http://www.census.gov/PressRelease/www/releases/archives/communication_industries/013849.html >.

Fjeld, T. 2005. Do plants in offices promote health? 11 Aug. 2009. <http:// plants-for-people.org/eng/science/office_ health.doc $>$.

Gilhooley, M.J. 2002. Green green grass of work: A little bit of green can go a long way, and we're not talking about money. Facilities Design Mgt. 21(9). 11 Aug. 2009. <http://goliath.ecnext.com/ coms2/gi_0198-113217/Green-greengrass-of-work.html>.

Klemmer, C.D. and S. Skelly. 2006. The changing face of education. Public Garden $21(2): 8-12$.

Lewis, C. 1991. A humanist role for public gardens. Amer. Assn. Botanical Gardens Arboreta Nwsl. 194:1.

Lohr, V., C. Pearson-Mims, and G. Goodwin. 1996. Interior plants may improve worker productivity and reduce stress in a windowless environment. J. Environ. Hort. 14(2):97-100.

Price, S.D. 2000. Growing home: Stories of ethnic gardening. University of Minnesota Press, Minneapolis.

Sernovitz, A. 2009. Word of mouth marketing. Kaplan Publishing, New York.

Tamulevich, S. 2006. Collecting a new species: Visitors. Public Garden 21(2):20-22.

Ulrich, R.S. 1984. View through a window may influence recovery from surgery. Science 224(4647):420-421.

Whitehouse, S.V.J., M. Seid, C. CooperMarcus, M. Ensberg, J. Jacobs, and R. Mehlenbeck. 2001. Evaluating a children's hospital garden environment: Utilization and consumer satisfaction. J. Environ. Psychol. 21:301-314. 